\title{
Current Trends in the Treatment of Dupuytren Disease in Spain
}

\section{Tendencias Actuales en el Tratamiento de la Enfermedad de Dupuytren en España}

\author{
Rafael Sanjuan-Cerveró ${ }^{1}$ Diego Gómez-Herrero ${ }^{2,3}$ Carlos Novoa-Parra ${ }^{1}$ Fernando Peña-Molina ${ }^{1}$ \\ Nuria Franco-Ferrando ${ }^{1}$ \\ 1 Orthopedic Surgery and Traumatology Service, Hospital de Denia \\ (Alicante), Alicante, Spain \\ 2 Pharmacy Service, Vithas Hospital 9 de Octubre, Valencia, Spain \\ 3 Pharmacy Doctorate Program, Universidad de Granada, Granada, Spain \\ Address for correspondence Rafael Sanjuan-Cerveró, MD, MS, PhD, \\ Servicio de Cirugía Ortopédica y Traumatología, Hospital de Denia, \\ Partida Beniadlá s/n. 03700, Denia (Alicante), Alicante, Spain \\ (e-mail: sanjuan.rafcer@gmail.com).
}

Rev Iberam Cir Mano 2020;48:10-19.

\begin{abstract}
Keywords

- dupuytren disease

- faciectomy

- collagenase

- survey

- treatment
\end{abstract}

Resumen
Objective Assessment of the treatment trends of Spanish surgeons in clinical practice by making clinical assumptions in Dupuytren's disease (DD).

Material and Method A survey was sent to the members of the Spanish Society for Surgery of the Hand (Sociedad Española de Cirugía de la Mano, SECMA) posing primary and secondary clinical cases. A relationship is established between the selected treatment, the characteristics of the participating surgeons, and the characteristics of the primary clinical cases. Treatment preferences in recurrences are assessed descriptively.

Results In total, 127 surveys were answered. $62.2 \%$ of the participants had experience with the use of collagenase and were the basis of the analysis. In primary cases, surgeons with more practice time tended to choose collagenase as treatment for DD. Surgeons who reported higher frequency of collagenase use (67.4\% vs. $25.7 \%$ ) were up to 6 times more likely to indicate such treatment. The patient's age under 50 years was the variable with the greatest association strength for the choice of collagenase treatment $(\mathrm{OR}=3.8 ; \mathrm{Cl} 95 \%$ 1.9-7.6). In recurrences, among all clinical cases, the most common answer given by the surgeons was partial fasciectomy.

Conclusions Partial fasciectomy continues to be the most widely used treatment for DD in Spain. In primary cases, collagenase is an alternative adopted by experienced surgeons, and in treatments for young patients. In recurrences, partial fasciectomy is the preferred technique.

Objetivo Valoración de las tendencias de tratamiento de los cirujanos españoles en la práctica clínica mediante la realización de supuestos clínicos en la enfermedad de Dupuytren (ED).

Material y Método Se remite una encuesta a los socios de la Sociedad Española de Cirugía de la Mano (SECMA) que plantea casos clínicos primarios y secundarios. Se received

September 15, 2019

accepted

February 20, 2020
DOI https://doi.org/

10.1055/s-0040-1712096. ISSN 1698-8396.
Copyright $\odot 2020$ Thieme Revinter

Publicações Ltda, Rio de Janeiro, Brazil
License terms

(c) $(1) \$$ 

Palabras clave
- enfermedad de dupuytren
- fasciectomía
- colagenasa
- encuesta

establece una relación entre el tratamiento seleccionado, las características de los cirujanos participantes y las características de los casos clínicos primarios. Se valoran las preferencias de tratamiento en las recurrencias de modo descriptivo.

Resultados En total, 127 encuestas fueron respondidas. El 62,2\% de los participantes tenía experiencia con el uso de la colagenasa y fueron la base del análisis. En los casos primarios, los cirujanos con más tiempo de ejercicio mostraron una tendencia a escoger colagenasa como tratamiento para la ED. Los cirujanos que informaban mayor frecuencia de uso de colagenasa $(67,4 \%$ vs $25,7 \%)$ tenían hasta 6 veces más probabilidad de indicar ese tratamiento. La edad menor a 50 años del paciente era la variable con mayor fuerza de asociación para la elección del tratamiento con colagenasa $(\mathrm{OR}=3,8 ;$ IC95\% 1,9-7,6). En las recurrencias, en todos los casos clínicos la respuesta mayoritariamente respondida por los cirujanos fue la fasciectomía parcial.

Conclusiones La fasciectomía parcial sigue siendo el tratamiento más utilizado en la ED en España. En los casos primarios, la colagenasa es una alternativa adoptada por cirujanos con experiencia y en tratamientos para pacientes jóvenes. En las recurrencias, la fasciectomía parcial es la técnica preferida.

\section{Introduction}

The survey sent by the Spanish Society for Surgery of the Hand (Sociedad Española de Cirugía de la Mano, SECMA) regarding the treatment of Dupuytren's disease (DD), included a series of clinical assumptions in which was posed the assessment of the current trend of treatment, considering practical cases. Comparison with previous data from the study of Muñoz-Peñin ${ }^{1}$ is not strictly applicable in this case, since that study design is different from this article, although we will refer to it when referring to the use of the different techniques used by surgeons. In the current medical literature only one article, ${ }^{2}$ recently done, performs an assessment using an international survey to assess current perspectives of DD treatment in a similar way. This survey, based on clinical cases, establishes a regional difference regarding the preference of hand surgeons for treatment with DD, encompassing the most common treatments today for primary processes: partial fasciectomy (PFSC), the needle aponeurotomy (NA) and treatment with Clostridium Histolyticum collagenase ( $\mathrm{CCH})$. The survey and the obtaining of results were carried out before the suspension of the commercialization of the $\mathrm{CCH}$ in late 2019.

Our objective is to assess, by carrying out clinical cases in the survey promoted by SECMA, and adapted to the most common therapeutic solutions today in our geographical area, the trend of Spanish surgeons in the treatment of DD.

\section{Material and Methods}

\section{Recruitment}

This study has been approved by SECMA and is part of the SPAINCOL project for the assessment of long-term CCH treatment. It was approved by the Institutional Ethical Committee (code CEI m38/19) and the Spanish Association of Medicines and Health Products (code AEMPS RSC-COL-2019-01).
The survey was tested on two members of the medical staff of the lead author's hospital; their responses were not included in the results. After that, it was sent by email to SECMA partners. A brief description of the survey, details of anonymity and the intention to publish the identified data was made on the first page. Both the general questions and the clinical assumptions were drawn up by the lead author and agreed with various hand surgeons and the SECMA research committee. It should be borne in mind that the survey was drafted, carried out and analyzed in the time before $\mathrm{CCH}$ was withdrawn from the European market.

\section{Instrument}

The variables analyzed in this study correspond to the block of questions from the survey provided by SECMA ranging from number 13 to 20 . Of these eight questions, the first four correspond to primary clinical cases and the following four to recurrences.

The questions were structured into five possible answers, leaving the last one open for the introduction of other treatment alternatives, which was analyzed separately but was considered unique for statistical analysis.

The results of these questions were analyzed in relation to the group of questions (5,6,9-12,21-23 25-27) about the general opinion of DD treatment (Annex 1).

\section{Interest groups}

For the study of the primary cases, the characteristics selected as representative were based on criteria of supposed severity or a higher rate of recurrence of the patients, such as: age younger than 50 years as a factor of greater aggressiveness present in cases of Dupuytren diathesis, ${ }^{3}$ involvement of one or more fingers, involvement of the $5^{\text {th }}$ finger, involvement of PIP and/or of the MCP and contracture less than or equal to $45^{\circ}$ considered mild, and greater as severe. This last value has been considered based on the severity 
12 Current Trends in the Treatment of Dupuytren Disease in Spain Sanjuan-Cerveró et al.

Table 1 Arrangement of variables according to the primary case

\begin{tabular}{|l|l|l|l|l|l|}
\hline Case & Age $>\mathbf{5 0}$ years & $\begin{array}{l}\text { Number of } \\
\text { affected fingers }\end{array}$ & $\begin{array}{l}\text { Is the } \mathbf{5}^{\text {th }} \text { finger } \\
\text { affected? }\end{array}$ & $\begin{array}{l}\text { More than } \mathbf{4 5}^{\circ} \text { contracture } \\
\text { (single joint or combined } \\
\text { in only } \mathbf{1} \text { finger) }\end{array}$ & Is PIP affected? \\
\hline $1(\mathrm{p} 13)$ & Yes & One & Yes & Yes & No \\
\hline $2(\mathrm{p} 14)$ & No & One & No & No & No \\
\hline $3(\mathrm{p} 15)$ & N/A & Two & Yes & Yes & Yes \\
\hline $4(\mathrm{p} 16)$ & No & One & No & No & Yes \\
\hline
\end{tabular}

$(\mathrm{pN})=$ Presumed number in the survey (Annex 1). Abbreviation: PIP, Promimal InterPhalangeal.

criteria established in the CORD studies ${ }^{4}$ to which was applied a variation of $5^{\circ}$ for possible measurement errors. ${ }^{5-7}$ The characteristics studied for each case are summarized in - Table 1.

For the study of recurrences, the analysis focused on the choice of technique, with assumptions that included recurrences after treatment with $\mathrm{CCH}$ or FSC and with the same variables as in primary cases. The definition of recurrence was made based on Felici's criteria. ${ }^{8}$

\section{Statistical Analysis}

Statistical analyzes were carried out using SPSS v.22. The results were shown as absolute and relative frequency. To assess whether there were differences between the number of times each technique was chosen according to the group, an analysis of $\mathrm{X}^{2}$ was used. To assess the strength of association between the variables, the Odds ratio (OR) was used for dichotomous variables and Cramer's V for ordinal variables. For all analyzes, statistical significance was considered for $\mathrm{p}$ values less than 0.05 .

For the assessment of preferences in cases of recurrence we have not performed a statistical analysis, considering the descriptive analysis sufficiently representative.

\section{Results}

\section{Sample}

The survey was sent to a total of 332 members of the Society. Of these, 127 (38.2\%) answered the survey, of which 79 (62.2\% of the respondents) had experience with the use of $\mathrm{CCH}$ and were chosen to assess preferences in primary cases. For the final evaluation of the primary clinical cases, only the surveys in which the $\mathrm{CCH}$ or FSC options had been selected were considered, since the number relative to the other options was marginal and not relevant for the analysis (-Table 2). Thus, 61 (48\%) of the surveys were analyzed.

\section{Results of Individual Preferences in Primary Cases}

When we analyze the influence of the characteristics of the surgeon and the treatment used, we find an association between this and the time he has been practicing the specialty since he finished his residency $\left(\mathrm{X}^{2} p=0.027\right)$, however that association has been weak $(\mathrm{V}=0.16)$. (-Table 3)

The treatment used also corresponded to the frequency of use of the treatment options and their preference. Surgeons who reported higher frequency of $\mathrm{CCH}$ use (67.4\% vs. $25.7 \%$ ) were up to 6 times more likely to indicate such treatment in primary cases. ( - Table $\mathbf{3}$ )

When the patients were 50 years old or younger $(53.3 \% \mathrm{vs}$. $23 \%$ ), the 5 th finger was free of disease (53.3\% vs. $29.5 \%$ ) and contracture was less than $50^{\circ}$ ( $53.3 \%$ vs. $29.5 \%$ ), participating surgeons preferred $\mathrm{CCH}$ treatment. The age of patients under 50 years was the variable with the strongest association with the choice of $\mathrm{CCH}$ as treatment $(\mathrm{OR}=3.8$; CI95\% 1.9-7.6) (-Table 4).

\section{Results of Recurrence Preferences}

In all cases, the preferred response by surgeons was FSC, ranging from $54.8 \%$ (question \# 20) to $83.7 \%$ (question \# 17). The predominant response was FSC in cases with involvement considered severe and patients over 50 years of age, as well as in those with combined involvement of the metacarpophalangeal joint (MCP) and the proximal interphalangeal joint (PIP). Question 19, which presented by a 72-year-old patient with combined involvement $(\mathrm{MCP}+\mathrm{PIP})$ of the 5th finger, was the only one in which the dermophasciectomy (DFSC) has had a considerable

Table 2 General results of the survey without specification of knowledge or not of the CCH for primary cases

\begin{tabular}{|l|l|l|l|l|l|l|}
\hline Clinical case & N & CCH & FSC & DFSC & NA & Other \\
\hline 13 & 120 & $24(19.4)$ & $95(76.6)$ & $4(3.2)$ & $4(3.2)$ & $10(8.1)$ \\
\hline 14 & 124 & $56(45.5)$ & $54(43.9)$ & $1(0.8)$ & $8(6.5)$ & $4(3.3)$ \\
\hline 15 & 123 & $23(19)$ & $91(75.2)$ & $1(0.8)$ & $1(0.8)$ & $5(4.1)$ \\
\hline 16 & 121 & $27(22.5)$ & $80(66.7)$ & $2(1.7)$ & $5(5.0)$ & $5(4.2)$ \\
\hline
\end{tabular}

Abbreviations: NA, needle aponeurotomy; CCH, collagenase; DFSC, dermofasciectomy; FSC, fasciectomy.

Data expressed in absolute value (\%). 
Table 3 Surgeon characteristics associated with the selected treatment

\begin{tabular}{|c|c|c|c|c|c|c|c|c|}
\hline \multicolumn{9}{|c|}{ Treatment selected in each case } \\
\hline Variable & Group $(N=61)^{\theta}$ & $\mathrm{CCH}^{*}$ & $\mathrm{FSC}^{*}$ & $p\left(X^{2}\right)$ & OR & $\mathrm{Cl}$ & $\begin{array}{l}\mathrm{p} \\
\text { (V Cramer) }\end{array}$ & $\begin{array}{l}\text { V } \\
\text { Cramer }\end{array}$ \\
\hline \multirow[t]{3}{*}{ Surgeon's age } & $<30$ years $(21)$ & $34(40.5 \%)$ & $50(59.5 \%)$ & \multirow[t]{3}{*}{0.976} & \multirow[t]{3}{*}{-} & \multirow[t]{3}{*}{-} & \multirow[t]{3}{*}{$0.977^{* *}$} & \multirow[t]{3}{*}{0.01} \\
\hline & $30-40$ years $(18)$ & $30(41.7 \%)$ & $42(58.3 \%)$ & & & & & \\
\hline & $40-50$ years $(22)$ & $37(42 \%)$ & $51(58 \%)$ & & & & & \\
\hline \multirow{4}{*}{$\begin{array}{l}\text { How many years have } \\
\text { you been practicing } \\
\text { your specialty since } \\
\text { your residency ended? }\end{array}$} & $<3$ years $(2)$ & $0(0.0 \%)$ & $8(100 \%)$ & \multirow[t]{4}{*}{0.027} & \multirow[t]{4}{*}{-} & \multirow[t]{4}{*}{-} & \multirow[t]{4}{*}{$0.098^{* *}$} & \multirow[t]{4}{*}{0.16} \\
\hline & $3-6$ years $(8)$ & $12(37.5 \%)$ & $20(62.5 \%)$ & & & & & \\
\hline & $6-15$ years $(21)$ & $36(42.9 \%)$ & $48(57.1 \%)$ & & & & & \\
\hline & $>15$ years $(30)$ & $53(44.2 \%)$ & $67(55.8 \%)$ & & & & & \\
\hline \multirow{5}{*}{$\begin{array}{l}\text { And as a surgeon } \\
\text { dedicated to } \\
\text { hand surgery? }\end{array}$} & $<3$ years $(2)$ & $2(25 \%)$ & $6(75 \%)$ & \multirow[t]{5}{*}{0.816} & \multirow[t]{5}{*}{-} & \multirow[t]{5}{*}{-} & \multirow[t]{5}{*}{$0.686^{* *}$} & \multirow[t]{5}{*}{0.08} \\
\hline & $3-6$ years $(9)$ & $15(41.7 \%)$ & $21(58.3 \%)$ & & & & & \\
\hline & $6-15$ years $(27)$ & $48(44.4 \%)$ & $60(55.6 \%)$ & & & & & \\
\hline & $>15$ years $(18)$ & $28(38.9 \%)$ & $44(61.1 \%)$ & & & & & \\
\hline & $\begin{array}{l}\text { General } \\
\text { Orthopedic/ } \\
\text { Plastic } \\
\text { surgeon (5) } \\
\end{array}$ & $8(40 \%)$ & $12(60 \%)$ & & & & & \\
\hline \multirow{2}{*}{$\begin{array}{l}\text { In Dupuytren's disease, } \\
\text { which of the following } \\
\text { treatments do you } \\
\text { use most frequently? }\end{array}$} & $\mathrm{CCH}(23)$ & $62(67.4 \%)$ & $30(32.6 \%)$ & \multirow[t]{2}{*}{$<0.001$} & \multirow[t]{2}{*}{6.0} & \multirow[t]{2}{*}{$3.3-10.6$} & \multirow[t]{2}{*}{-} & \multirow[t]{2}{*}{-} \\
\hline & FSC (38) & 39 (25.7\%) & $113(74.3 \%)$ & & & & & \\
\hline \multirow{3}{*}{$\begin{array}{l}\text { Regardless of } \\
\text { frequency, what } \\
\text { is your preferred } \\
\text { treatment? }\end{array}$} & $\mathrm{CCH}(30)$ & 75 (62.5\%) & 45 (35.7\%) & \multirow[t]{3}{*}{$<0.001$} & \multirow[t]{3}{*}{-} & \multirow[t]{3}{*}{-} & \multirow[t]{3}{*}{-} & \multirow[t]{3}{*}{-} \\
\hline & FSC (30) & $23(19.2 \%)$ & $97(80.8 \%)$ & & & & & \\
\hline & NA (1) & $3(75 \%)$ & 1 (25\%) & & & & & \\
\hline
\end{tabular}

Abbreviations: NA, needle aponeurotomy; CCH, collagenase; DFSC, dermofasciectomy; FSC, fasciectomy.

*Absolute number of options selected by all cases (Number relative to group).

${ }^{* *}$ Calculated for ordinal groups (years).

${ }^{\theta}$ Number of affirmative answers in the survey indicated in parentheses in each of the assumptions.

Table 4 Patient characteristics associated with the selected treatment

\begin{tabular}{|c|c|c|c|c|c|c|c|c|}
\hline \multicolumn{9}{|c|}{ Selected treatments in each case } \\
\hline Variable & Group & $\mathrm{CCH}^{*}$ & $\%$ & FSC $^{*}$ & $\%$ & $\mathrm{p}$ & OR & $\mathrm{Cl}$ \\
\hline \multirow[t]{2}{*}{ Age } & Less than or equal to 50 years & 65 & 53.3 & 57 & 46.7 & \multirow[t]{2}{*}{$<0.001$} & \multirow[t]{2}{*}{3.8} & \multirow[t]{2}{*}{ 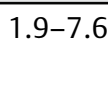 } \\
\hline & Over 50 years & 14 & 23.0 & 47 & 77.0 & & & \\
\hline \multirow[t]{2}{*}{ Number of affected fingers } & One finger & 79 & 43.2 & 104 & 56.8 & \multirow[t]{2}{*}{0.37} & \multirow[t]{2}{*}{1.3} & \multirow[t]{2}{*}{$0.7-2.4$} \\
\hline & Two or more fingers & 22 & 36.1 & 39 & 63.9 & & & \\
\hline \multirow[t]{2}{*}{ Is the $5^{\text {th }}$ finger affected? } & No & 65 & 53.3 & 57 & 46.7 & \multirow[t]{2}{*}{$<0.001$} & \multirow[t]{2}{*}{2.7} & \multirow[t]{2}{*}{$1.6-4.6$} \\
\hline & Yes & 36 & 29.5 & 86 & 70.5 & & & \\
\hline \multirow{2}{*}{$\begin{array}{l}\text { Does it have more than } \\
45^{\circ} \text { of contracture? }\end{array}$} & No & 65 & 53.3 & 57 & 46.7 & \multirow[t]{2}{*}{$<0.001$} & \multirow[t]{2}{*}{2.7} & \multirow[t]{2}{*}{$1.6-4.6$} \\
\hline & Yes & 36 & 29.5 & 86 & 70.5 & & & \\
\hline \multirow[t]{2}{*}{ Is PIP affected? } & No & 58 & 47.5 & 64 & 52.5 & \multirow[t]{2}{*}{0.069} & \multirow[t]{2}{*}{1.6} & \multirow[t]{2}{*}{$0.9-2.7$} \\
\hline & Yes & 43 & 35.2 & 79 & 64.8 & & & \\
\hline
\end{tabular}

Abbreviations: $\mathrm{CCH}$, collagenase; FSC, fasciectomy; PIP, Proximal interphalangeal.

*Absolute number of options selected by all cases. \% Group number.

response rate $(8.7 \%)$ as well as other alternatives $(6.1 \%)$, including amputation among free field responses. Treatment with $\mathrm{CCH}$ was considered as an alternative in cases of recurrence in those cases of young patients, with isolated involvement of the MCP and central radius mild contracture, independently of the treatment previously performed with FSC (31\%) or CCH (29.3\%). The results are consistent with the subjective opinions of the surgeons, in which 
Table 5 Results of clinical cases in the cases presented as recurrences

\begin{tabular}{|l|l|l|l|l|l|l|l|l|l|l|}
\hline CASE & Age & Finger & Severity & Joint & Previous Treatm & CCH $^{*}$ & FSC $^{*}$ & DFSC $^{*}$ & NA $^{*}$ & Other $^{*}$ \\
\hline 17 & $>50$ & 5 & $>45$ & MCP + PIP & CCH & 6.8 & 83.8 & 0.9 & 3.4 & 5.1 \\
\hline 18 & $<50$ & 4 & $\leq 45$ & MCP & CCH & 29.3 & 63.8 & 0.9 & 3.4 & 2.6 \\
\hline 19 & $>50$ & 5 & $>45$ & MCP + PIP & FSC & 12.2 & 70.4 & 8.7 & 2.6 & 6.1 \\
\hline 20 & $<50$ & 4 & $\leq 45$ & MCP & FSC & 31 & 54.9 & 8 & 3.5 & 2.7 \\
\hline
\end{tabular}

Abbreviations: NA, needle aponeurotomy; Joint, affected joint (MCP, metacarpal phalangeal; PIP, Proximal interphalangeal); CCH, collagenase; FSC, fasciectomy; DFSC, dermo-fasciectomy.

Case considered as the corresponding question of the survey promoted by SECMA (Annex 1), age considered in years, severity in degrees.

*Results expressed in (\%) of the total responses.

$82.2 \%$ (88) preferred FSC as the technique of choice. (-Table 5).

\section{Discussion}

Our results indicate that the preferred and most used treatment for DD continues to be FSC. However, we have defined that $\mathrm{CCH}$ has been established as a second treatment option. There is also a clear decrease in DFSC.

If we compare our results with those previously published in $\operatorname{Spain}^{1}$ (-Table 6), FSC is considered the treatment of choice today in even more cases. A curious fact from the 2011 study is that almost $12 \%$ of surgeons advocate the use of a radical FSC, a technique little used today and not without serious complications ${ }^{9-12}$ for primary cases. The trend of our surgeons seems to guide the current preference towards minimally invasive techniques in the treatment of $\mathrm{DD}$, since they allow a quick recovery of the patient with the minimum impact, leaving only the most demanding techniques for those severe cases and pronounced recurrences, as various authors have sustained. ${ }^{13,14}$

Regarding primary cases, we have observed that the participating surgeons with more time as specialists in hand surgery tend to choose $\mathrm{CCH}$ as treatment for DD. Similarly, those who report higher frequency of its use in routine practice are more likely to select $\mathrm{CCH}$ as the treatment method. The baseline characteristics of the patients influence this choice, the most important being age. In the USA, a survey sent to members of the American Society for Surgery of the Hand (ASSH), ${ }^{15}$ indicates that for simple primary cases, the technique preferred by surgeons is $\mathrm{CCH}$, leaving FSC for more complex cases with combined involvement of MCP and PIP, and seeing how minimally invasive techniques are predominant in cases of primary involvement

Table 6 Comparison between the DD treatment situation presented in $2011^{1}$ and the current one. Results expressed in $\%$ of the total survey responses in each case.

\begin{tabular}{|l|l|l|l|l|l|}
\hline Year & parcial FSC & radical FSC & DFSC & NA & CCH \\
\hline 2011 & 51.70 & 11.80 & 12.20 & 12.20 & N/A \\
\hline 2019 & 73 & N/A & 0.8 & 2.4 & 23 \\
\hline
\end{tabular}

Abbreviations: NA, needle aponeurotomy; $\mathrm{CCH}$, Collagenase Clostridium Histolitycum; DFSC, Dermofasciectomy; FSC, Fasciectomy. and with the consideration of "best treatment," results similar to the trend that we are observing in Spain. In Switzerland, ${ }^{16} \mathrm{CCH}$ use has also been increasing in recent years, especially by younger surgeons, unlike what happens here, although FSC is still the treatment of choice.

Observing our results, it is curious that in those young patients (under 50 years of age in our study), $\mathrm{CCH}$ is increasing as a technique of choice in both primary and secondary cases. Although it is true that the clinical cases presented in both primary and recurrence situations represent relatively simple cases, with the predominant involvement of a central and major finger of the MCP, young age has been classically considered as one of the factors of poor prognosis in DD, with more aggressive techniques being endorsed due to the possibility of recurrences due to the concept of Dupuytren diathesis established by Hueston. ${ }^{11}$ All these regional variations are influenced by regulatory, political, economic or logistical factors ${ }^{17,18}$ therefore the data shown in our study cannot be extrapolated to other populations.

The only reference to an article that bases its conclusions on clinical assumptions and that includes $\mathrm{CCH}$ as an alternative treatment is established by McMillan. ${ }^{2}$ In his case, the variables analyzed are the thickness of the cord, the severity of the contracture, the age, and the affected joint. Although this is a study covering surgeons from various countries, the number of respondents is relatively small (36 surgeons with expertise in hand surgery), so the results may not show the reality of treatment worldwide. As it is the only study at the international level, in its discussion it mentions how $\mathrm{CCH}$ is most used in the USA and Australia, indicating a certain predisposition of surgeons in northern Europe to use NA. We agree in his statement that there is little consistency in the DD treatment recommendations, and the lack of consensus among the scientific community and our results support this.

Currently the assessment of the need for treatment is often based on the decision of the patients' need or not, ${ }^{19}$ leaving aside the classic assessment of the degree of contracture and making those assessments for treatment planning, as we saw in the results of the global survey carried out in Spain. Proof of this is the assessment of pre and post treatment states with tools such as PROM (Patient Reported Outcome Measures) and PREM (Patient Reported Experience Measures), ${ }^{20-23}$ although like everything with DD there is inconsistency in terms of results and consensus. ${ }^{24}$ 
In the recurrences section, the preferred technique in all cases is FSC by far. Drawing conclusions with the results of four standardized clinical cases is somewhat risky, but in our opinion we see how the more aggressive techniques are detrimental in favor of performing a new FSC in the event of recurrence and that $\mathrm{CCH}$ is an alternative in those cases in which it has demonstrated its efficacy, that is, isolated involvement of the MCP with non-severe contraction in the central radius. Although it is true that more and more treatment is individualized for the patient, recurrence tends to be valued as another primary disease (whenever conditions allow), not neglecting any therapeutic alternative if its use is possible. Recurrence as a workhorse of DD, and the prospect of maintaining viable tissues in the face of the possibility of new future involvement, is a determining factor at the time of determining the treatment of recurrences.

As for the limitations of our study, they are the same as those presented in the gross results of the general survey, that is: the results of a survey that shows only the subjective opinions of the participants, the lack of uniformity of the responses presented allows only a partial comparison of the results obtained, fatigue in conducting the survey, biases produced by unanswered responses, and sample error produced with the recruitment of participants.

In conclusion, we can say that FSC is still the most used treatment for DD in Spain based on clinical assumptions. In primary cases, $\mathrm{CCH}$ has displaced other techniques as a second treatment option for DD. The selection of $\mathrm{CCH}$ as the primary treatment was associated with a longer time as a specialist in hand surgery, with choosing $\mathrm{CCH}$ as the most frequently used treatment, and with the age of the patient being less than 50 years. In recurrences, FSC is, without a doubt, the most widely used technique.

\section{Conflict of interests}

The authors declare that have no conflict of interests.

\section{References}

1 Muñoz-Peñin R, Lwoff N, Renú JMA. Enfermedad de Dupuytren, una vista panorámica de nuestro entorno. Rev Iberoam Cir Mano 2011;39(02):126-134

2 McMillan C, Yeung C, Binhammer P. Variation in treatment recommendations for Dupuytren disease. J Hand Surg Am 2017;42(12):963-970.e6

3 Hueston JT. Dupuytren's contracture: The trend to conservatism. Ann R Coll Surg Engl 1965;36(03):134-151

4 Hurst LC, Badalamente MA, Hentz VR, et al; CORD I Study Group. Injectable collagenase clostridium histolyticum for Dupuytren's contracture. N Engl J Med 2009;361(10):968-979

5 Engstrand C, Krevers B, Kvist J. Interrater reliability in finger joint goniometer measurement in Dupuytren's disease. Am J Occup Ther 2012;66(01):98-103

6 Broekstra DC, Lanting R, Werker PMN, van den Heuvel ER. Intraand inter-observer agreement on diagnosis of Dupuytren disease, measurements of severity of contracture, and disease extent. Man Ther 2015;20(04):580-586

7 Ellis B, Bruton A. A study to compare the reliability of composite finger flexion with goniometry for measurement of range of motion in the hand. Clin Rehabil 2002;16(05):562-570

8 Felici N, Marcoccio I, Giunta R, et al. Dupuytren contracture recurrence project: reaching consensus on a definition of recurrence. Handchir Mikrochir Plast Chir 2014;46(06):350-354

9 Clarkson P. The radical fasciectomy operation for Dupuytren's disease: a condemnation. Br J Plast Surg 1963;16:273-279

10 Hakstian RW. Long-term results of extensive fasciectomy. Br J Plast Surg 1966;19(02):140-149

11 Hueston JT. Limited fasciectomy for Dupuytren's contracture. Plast Reconstr Surg Transplant Bull 1961;27(06):569-585

12 McGrouther DA. La maladie de Dupuytren. To incise or excise? J Hand Surg [Br] 1988;13(04):368-370

13 Lipman MD, Carstensen SE, Deal DN. Trends in the treatment of Dupuytren disease in the United States between 2007 and 2014. Hand (N Y) 2017;12(01):13-20

14 Thayer MK, Somerson JS, Huang JI. Changes in provider treatment patterns for Dupuytren's contracture: Analysis of trends in Medicare beneficiaries. Plast Reconstr Surg Glob Open 2018;6(10): e1932

15 Carr L, Michelotti B, Brgoch M, Hauck R, Ingraham J. Dupuytren disease management trends: A Survey of Hand Surgeons. Hand (N Y) 2020;15(01):97-102

16 Marks M, Krefter C, Herren DB. Treatment methods for patients with Dupuytren's disease in Switzerland. Handchir Mikrochir Plast Chir Organ Deutschsprachigen Arbeitsgemeinschaft Handchir Organ Deutschsprachigen Arbeitsgemeinschaft Mikrochir Peripher Nerven Gefasse Organ V 2016;48(03):155-160

17 Leskelä R-L, Herse F, Torkki P, Laine J, Vilkuna T, Raatikainen T. Analysis of the adoption of new health technology: the case of Dupuytren's disease. Int J Healthc Technol Manag 2016;15(03): 210-227

18 Pajardi G, Parolo C, Willbrand S, Hurst L, Grablutz LB. American and european regulations. In: Collagenase in Dupuytren disease. SpringerCham2018:119-130

19 Au-Yong ITH, Wildin CJ, Dias JJ, Page RE. A review of common practice in Dupuytren surgery. Tech Hand Up Extrem Surg 2005;9 (04):178-187

20 Beaudreuil J, Allard A, Zerkak D, et al; URAM Study Group. Unité Rhumatologique des Affections de la Main (URAM) scale: development and validation of a tool to assess Dupuytren's diseasespecific disability. Arthritis Care Res (Hoboken) 2011;63(10): 1448-1455

21 Engstrand C, Kvist J, Krevers B. Patients' perspective on surgical intervention for Dupuytren's disease - experiences, expectations and appraisal of results. Disabil Rehabil 2016;38(26): 2538-2549

22 Eppler SL, Kakar S, Sheikholeslami N, Sun B, Pennell H, Kamal RN. Defining Quality in Hand Surgery From the Patient's Perspective: A Qualitative Analysis. J Hand Surg Am 2019;44(04):311-320.e4

23 Poelstra R, Selles RW, Slijper HP, et al; Hand-Wrist Study Group. Better patients' treatment experiences are associated with better postoperative results in Dupuytren's disease. J Hand Surg Eur Vol 2018;43(08):848-854

24 Ball C, Pratt AL, Nanchahal J. Optimal functional outcome measures for assessing treatment for Dupuytren's disease: a systematic review and recommendations for future practice. BMC Musculoskelet Disord 2013;14:131 


\section{Annex 1 Surveys sent to SECMA partners SURVEY ON TREATMENT TECHNIQUES FOR DUPUYTREN'S CONTRACTURE}

1-. How long have you been practicing in your speciality area (not counting residency period)?
A) Less than 3 years
B) 3-6 years
C) $6-15$ years
D) More than 15 years

2-. And how long have you been working as a hand surgeon?
A) Less than 3 years
B) 3-6 years
C) 6-15 years
D) More than 15 years

3-. Which autonomous community do you do most of your work in?

4-. How old are you?
A) Less than 30
B) $30-40$
C) $40-50$
D) More than 50

5-. Which of the following treatments do you use most in Dupuytren's contracture?
A) Collagenase injection
B) Partial open fasciectomy
C) Dermofasciectomy
D) Percutaneous Needle Aponeurotomy
E) Other techniques, please specify:

6-. Do you have experience using collagenase clostridium histolyticum $(\mathrm{CCH})$ to treat Dupuytren's contracture?
A) Yes
B) No

7-. In your opinion, what is the main advantage of $\mathrm{CCH}$ ? You can choose more than one option.
A) Cost-effective for the healthcare system
B) Few treatment-related complications
C) Rapid recovery and return to normal life
D) Surgical convenience
E) All of the above
F) None of the above

8-. And the main disadvantage(s)?
A) Recurrence rate
B) Need for more than one dose in patients with multiple cords or several affected fingers
C) Not being able to bill for this procedure in certain hospitals
D) Need to see the patient on two separate days
E) All of the above
F) None of the above

9-. Regardless of how often you use different treatments, which treatment do you prefer?
A) Collagenase injection
B) Partial open fasciectomy
C) Dermofasciectomy
D) Percutaneous Needle Aponeurotomy
E) Other techniques, please specify:

10-. Do you use any of these approaches to treat special cases? You can choose more than one.
A) Z plasties
B) Open palm technique
C) Pedicled flaps
D) Non pedicled flaps 

E) Amputations
F) PIP Arthrolisis
G) Other techniques, please specify:

11-. Has your approach to treating Dupuytren's contracture changed in the last 5 years?
A) Yes
B) No
C) I have been treating Dupuytren's disease for less than 5 years

12-. In general, how has the approach to treating Dupuytren's contracture changed? You can choose more than one option.
A) $\mathrm{CCH}$ is being used more.
B) Needle aponeurotomy is being used more.
C) Radical surgical approaches are being used less.
D) Other:

13-. In routine practice, what would be your preferred treatment for a 75-year-old patient with a contracture $>70^{\circ}$ in the proximal interphalangeal joint (PIP) of the little finger and an uninvolved metacarpophalangeal (MCP) joint?
A) Collagenase injection
B) Partial open fasciectomy
C) Dermofasciectomy
D) Percutaneous Needle Aponeurotomy
E) Other techniques, please specify:

14-. In routine practice, what would be your preferred treatment for a 45 -year-old patient with a $40^{\circ}$ contracture in the MCP joint of the middle finger and an uninvolved PIP joint?
A) Collagenase injection
B) Partial open fasciectomy
C) Dermofasciectomy
D) Percutaneous Needle Aponeurotomy
E) Other techniques, please specify:

15-. In routine practice, what would be your preferred treatment for a patient with contractures affecting the ring and little finger in which the total angle is $>45^{\circ}$ counting the MCP and PIP joints (MCP, PIP or MCP + PIP)?
A) Collagenase injection
B) Partial open fasciectomy
C) Dermofasciectomy
D) Percutaneous Needle Aponeurotomy
E) Other techniques, please specify:

16-. In routine practice, what would be your preferred treatment for a 45 -year-old patient with a nodule in the first phalanx of the middle finger and a contracture of $30^{\circ}$ in the MCP joint and $15^{\circ}$ in the PIP joint?
A) Collagenase injection
B) Partial open fasciectomy
C) Dermofasciectomy
D) Percutaneous Needle Aponeurotomy
E) Other techniques, please specify:

17-. In routine practice, what would be your preferred treatment for a 72-year-old patient previously treated with $\mathrm{CCH}$ presenting with a $20^{\circ}$ contracture in the MCP joint and a $40^{\circ}$ contracture in the PIP joint of the fifth finger?
A) Collagenase injection
B) Partial open fasciectomy
C) Dermofasciectomy
D) Percutaneous Needle Aponeurotomy
E) Other techniques, please specify:

18-. In routine practice, what would be your preferred treatment for a 50-year-old patient previously treated with $\mathrm{CCH}$ presenting with a $40^{\circ}$ contracture in the MCP joint of the ring finger?
A) Collagenase injection
B) Partial open fasciectomy
C) Dermofasciectomy
D) Percutaneous Needle Aponeurotomy
E) Other techniques, please specify: 
19-. In routine practice, what would be your preferred treatment for a 72-year-old patient previously treated with partial fasciectomy presenting with a $20^{\circ}$ contracture in the MCP joint and a $40^{\circ}$ contracture in the PIP joint of the little finger?

A) Collagenase injection

B) Partial open fasciectomy

C) Dermofasciectomy

D) Percutaneous Needle Aponeurotomy

E) Other techniques, please specify:

20-. In routine practice, what would be your preferred treatment for a 50-year-old patient previously treated with partial fasciectomy presenting with a $40^{\circ}$ contracture in the MCP joint of the fourth finger?

A) Collagenase injection

B) Partial open fasciectomy

C) Dermofasciectomy

D) Percutaneous Needle Aponeurotomy

E) Other techniques, please specify:

21-. Which is the most important factor for you when planning a new treatment for a patient with recurrent disease?

A) Degree of contracture in affected area

B) Functional outcome

C) Presence of palpable pretendinous cord

D) Condition of skin due to previous surgeries

22-. Generally speaking, which treatment do you use most for recurrent cases?
A) Collagenase injection
B) Partial open fasciectomy
C) Dermofasciectomy
D) Percutaneous Needle Aponeurotomy
E) Other techniques, please specify:

23-. Supposing that you have performed a partial fasciectomy in a patient with recurrent disease following initial treatment with $\mathrm{CCH}$, how would define the anatomy of the surgical area?
A) Completely normally
B) Altered, making surgery more complicated
C) Completely abnormal, with no resemblance to a typical Dupuytren cord
D) Variable depending on the case, but with an atypical cord
E) I have not seen any cases like this

24-. Personally, how would you rate $\mathrm{CCH}$ treatment?

A) Satisfactory, I use it as a routine procedure.

B) Satisfactory, but I still mostly use other techniques.

C) I think that $\mathrm{CCH}$ has its indications, but personally I don't use it.

D) I don't believe that CCH offers any advantages in the treatment of Dupuytren's contracture.

E) Completely unsatisfactory. $\mathrm{CCH}$ should be eliminated as an option for Dupuytren's contracture.

25-. In your experience, which treatment offers patients the best satisfaction in terms of short-term outcomes?
A) Collagenase injection
B) Partial open fasciectomy
C) Dermofasciectomy
D) Percutaneous Needle Aponeurotomy
E) Other techniques, please specify:

26-. And long-term outcomes?
A) Collagenase injection
B) Partial open fasciectomy
C) Dermofasciectomy
D) Percutaneous Needle Aponeurotomy
E) Other techniques, please specify:

27-. How do you normally assess treatment outcomes? (You can choose more than one option)

A) I measure improvements in finger extension.

B) I measure improvements in Tubiana classification.

C) I use a specific questionnaire (DASH, QuickDASH, MHS, BriefMHS, URAM...)

D) I evaluate the patient's subjective satisfaction 
28-. The landmark CORD studies recommended using up to three $\mathrm{CCH}$ injections to achieve full extension. Nonetheless, for reasons mainly related to cost-effectiveness and availability, several authors have published reports on the use of single doses, regardless of outcomes. In light of the above, what is your position on this?

A) I started out using the recommended CORD protocol, but no longer use it.

B) I started out using the recommended CORD protocol and still use it.

C) I have never used the CORD protocol.

29-. Have any of your patients developed complications that you would classify as serious as a result of CCH treatment?

A) No

B) Yes. Please specify:

30-. There have been several recent reports of authors using doses higher than the recommended dose of $0.58 \mathrm{mg}$ for $\mathrm{CCH}$ injections? Do you ever alter the recommended dose? You can choose more than one option.

A) No, I always use the standard dose and dispose of any remaining liquid.

B) I normally use a higher dose, i.e., I use the full vial.

C) I have sometimes injected two doses into the same finger or hand to complete the treatment in one session.

D) I have sometimes administered injections in both hands in patients with bilateral involvement. 